\title{
EDITORIAL
}

\section{Goodbye and farewell to Endocrine Connections!}

\author{
J Köhrle(i) \\ Berlin, Germany \\ Correspondence should be addressed to J Köhrle: josef.koehrle@charite.de
}

Endocrine Connections

(2021) 10, E1-E2

Endocrine Connections was launched by the European Society of Endocrinology (ESE) and the Society for Endocrinology (SfE) with two issues in 2012. It was the first open access journal devoted entirely to the research of hormones.

In 2016, when I was asked to follow Jens Sandahl Christiansen as Editor-in-Chief after his unexpected and much too early death, Endocrine Connections had just been included in the Science Citation Index Expanded (SCIE).

Based on the journal's regular publication of widely distributed and cited original articles and timely reviews on topical endocrine subjects, Endocrine Connections received its first Impact Factor in 2017. As of today as a relatively new scientific journal, I leave it well positioned in the field of endocrinology and metabolism.

Our highly committed Editorial Board, composed of internationally renowned Strategic and Senior Editors as well as expert Editorial Board members, covers the broad spectrum of endocrinology. Jointly, they are the essential core team for what has come to be a rigid, efficient, and constructive peer-review system in our journal.

The efforts of the Editorial Board in convincing and motivating a world-wide network of scientists to altruistically devote their scarce spare time on delivering scientifically sound, fair and speedy reviews for submitted papers, has been the key to providing a first decision response to submitting authors in less than 30 days. With such a highly professional team and extraordinary effort by our reviewers, the Editorial Board and our Editorial Office, the journal reached a rewarding milestone - two submissions per day during the last year.

I have felt that during my time as an Editorial Board member, I learned more about endocrinology and its connected biomedical areas than during the decades before I got involved with the journal. I only have many thanks and my highest esteem for all those involved over these years in supporting and advancing Endocrine Connections!
Gold open access publication, like that found in our journal, will remain one of the major roads to travel for current and future science publication in a multilateral, diverse, inclusive, and democratic world.

In this way, publications will be immediately accessible after the critical and high standard peer-review process, eventually leading to acceptance of submissions. Published work can then be freely read, downloaded and further discussed by both the interested scientific community and public from Alaska to New Zealand, from Cape Town to Norway, or even from Patagonia to Kamchatka (limited only by internet access!).

It is only through innovative science, new ideas, novel methodology, rigorous implementation and control of data and facts, plausibility tests and demonstration of cause-effect relationships beyond associations that there will be advances in knowledge to improve health and cure diseases, prevent and eliminate dreadful pandemics as well as the hunger of both a highly mobile and steadily growing population on our blue planet. As Bob Dylan has it, 'Come gather 'round people, wherever you roam and admit that the waters around you have grown ...'.

One of the missions of Endocrine Connections is tocover and connect classical endocrinology with intersecting hormone-related disciplines in the wider biomedical community. Therefore, we started to develop new topic sections such as 'Endocrinology of Chronic Disease', 'Endocrinology of the Nervous System and Behaviour' as well as 'Endocrine-Disrupting Chemicals'. The latter has gained significant momentum both with the communication of the 'Chemicals Strategy for Sustainability - Towards a Toxic-Free Environment' by the European Commission in October 2020, and the implementation of the Focus Area 'Environmental Endocrinology' by the Executive Committee of the ESE last year. Since Endocrine Disruptors now are classified as substances of very high concern (SVHC) similar to carcinogens, mutagens and reprotoxic (CMR) agents, which had this SVHC status before, endocrinologists (basic, translational and clinical!) in close cooperation with toxicologists, developmental biologists and

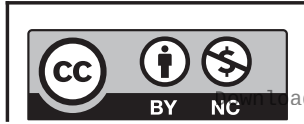

This work is licensed under a Creative Commons Attribution-NonCommercial 4.0 International License. ded from Bioscientifica.com at 04/26/2023 12:52:28AM 
nutrition scientists will have access to Endocrine Connections as a gold open access platform to communicate their expert knowledge and data on endocrine-disrupting chemicals to the interested audiences, communities and patients of the world.

We all do hope that the current Covid-19 pandemic, which disrupted life, science, publishing processes and most aspects of our social and professional life in all societies, will not result in increased incidence and/or new variants of endocrine-related diseases to be scientifically covered in our recently introduced journal topic section 'Endocrinology of Chronic Disease'.

We learned during the first year of this pandemic that major endocrine diseases such as diabetes, obesity and related cardiovascular conditions are strongly associated with increased morbidity and mortality of Sars-Cov-2 infected individuals, clearly indicating connections between endocrinology, infectious diseases and their prevention and treatment.

Whilst Endocrine Connections has steadily grown, it has stringently retained its science-driven course in occasionally stormy waters, stirred up by the highly competitive publication market (and some rookie predators!). Under the expert leadership of our new Editor-in-Chief Adrian Clark, supported by the excellent Editorial Board and the professional Editorial Office, Endocrine Connections will thrive and keep course.

I am strongly convinced that the fair, science-based and anonymous peer-review process is crucial to the progress of global science. This is one of my encouragements to my successor Adrian Clark (who now is the third Editor-inChief of Endocrine Connections), to the Editorial Board and to the endocrinology-oriented scientific communities in Anchorage, Cape Town, Caracas, Dakar, Djibouti, Halifax, Lisbon, Murmansk, Punta Arenas, Provideniya, Recife, Wellington, Yakutzk, and Yokohama; 'Come writers and critics, who prophesize with your pen, and keep your eyes wide, the chance won't come again ... for the times they are a-changin' '.

The classical peer-review system eventually may need further development, for example by a two-stage review process including 'registered reports', pre-prints or inclusion of elements of the 'swarm intelligence'.

'Since its launch in 2012 the journal has been growing steadily in quality, published content and its global readership' wrote the presidents of the ESE and the Society for Endocrinology in their invitation letter to me in shouldering the task as the new Editor-in-Chief for this journal, 5 years ago. Our new Editor-in-Chief Adrian Clark will now ignite stage three for Endocrine Connections, relying on the experienced ground control by the Editorial Office at Bioscientifica, the continuous strategic input and scientific support provided by the ESE and SfE, the entire Editorial Board, and the whole scientific community of authors and reviewers.

Josef Köhrle, January 2021

\section{Declaration of interest}

The author declares that there is no conflict of interest that could be perceived as prejudicing the impartiality of this editorial.

\section{Funding}

This work did not receive any specific grant from any funding agency in the public, commercial or not-for-profit sector.

Received in final from 28 January 2021

Accepted 28 January 2021

Accepted Manuscript published online 30 January 2021
This work is licensed under a Creative Commons Attribution-NonCommercial 4.0 International License. ded from Bioscientifica.com at 04/26/2023 12:52:28AM via free access 